\title{
Integration of Clearance Mechanisms: The Proteasome and Autophagy
}

\author{
Esther Wong and Ana Maria Cuervo \\ Department of Developmental and Molecular Biology, Institute for Aging Studies, \\ Albert Einstein College of Medicine, Bronx, New York 10461 \\ Correspondence: ana-maria.cuervo@einstein.yu.edu
}

Cells maintain a healthy proteome through continuous evaluation of the quality of each of their proteins. Quality control requires the coordinated action of chaperones and proteolytic systems. Chaperones identify abnormal or unstable conformations in proteins and often assist them to regain stability. However, if repair is not possible, the aberrant protein is eliminated from the cellular cytosol to prevent undesired interactions with other proteins or its organization into toxic multimeric complexes. Autophagy and the ubiquitin/proteasome system mediate the complete degradation of abnormal protein products. In this article, we describe each of these proteolytic systems and their contribution to cellular quality control. We also comment on the cellular consequences resulting from the dysfunction of these systems in common human protein conformational disorders and provide an overview on current therapeutic interventions based on the modulation of the proteolytic systems.

\begin{abstract}
$A^{s}$ described in previous articles on this sub-
Aject, cells count on a complex network of molecular chaperones that assist proteins in folding and help stabilize the transient conformations that proteins adapt for trafficking across membrane and during their assembly and disassembly into functional complexes (Large et al. 2009; Willis et al. 2009; Koga et al. 2010). However, different physiological and pathological conditions may overwhelm the homeostatic capability of the chaperone network and favor protein aggregation. For example, conditions resulting in massive protein unfolding such as acute oxidative stress or heat shock, chronically proaggregating conditions that deplete cells of critical chaperones, and abnormal high levels of prone-to-aggregate
\end{abstract}

pathogenic proteins can all make the refolding activity of chaperones insufficient to maintain proteome stability and prevent proteotoxicity (Morimoto 2008; Douglas et al. 2009; Koga et al. 2010). Under these conditions and for those proteins in which refolding is no longer possible, cells count on proteolytic systems to eliminate the unstable protein(s) and to recycle their amino acids (Willis et al. 2009). The lysosomal system and the ubiquitin/proteasome system (UPS), the two main proteolytic systems in cells, along with the molecular chaperones, constitute essential components of the cellular quality control systems (Ciechanover 2005). In this article, we briefly summarize the current knowledge regarding the molecular components of each of these proteolytic systems and

Editors: Richard Morimoto, Jeffrey Kelly, and Dennis Selkoe

Additional Perspectives on Protein Homeostasis available at www.cshperspectives.org

Copyright (C) 2010 Cold Spring Harbor Laboratory Press; all rights reserved; doi: 10.1101/cshperspect.a006734

Cite this article as Cold Spring Harb Perspect Biol 2010;2:a006734 
expand on recent evidence supporting the critical participation of both systems in the cellular defense against proteotoxicity. We also describe recently established connections between malfunctioning of these proteolytic systems and the pathogenesis of common protein conformational disorders with main emphasis on neurodegenerative diseases.

\section{INTRACELLULAR CLEARANCE MECHANISMS}

Cells maintain a state of self-renewal, through the continuous synthesis and degradation of all intracellular components, including soluble proteins and organelles (Ciechanover 2005). Added to this regulated turnover, the activity of the cellular degradative systems is up-regulated in response to protein or organelle damage and to replenish the intracellular reserve of free amino acids that sustains protein synthesis even in the absence of nutrients. Failure of the proteolytic systems to maintain basal cellular turnover or to accommodate to the degradative requirements of cells under stress conditions leads to altered cellular homeostasis, compromises the cellular energetic balance and often promotes intracellular accumulation of damaged components (Koga et al. 2010). Deposits of conformationally altered proteins that organize into insoluble oligomeric structures are toxic for cells and lead to cell death in common human pathologies generically known as protein conformational disorders (Markossian and Kurganov 2004; Morimoto 2008; Robinson 2008) (Fig. 1).

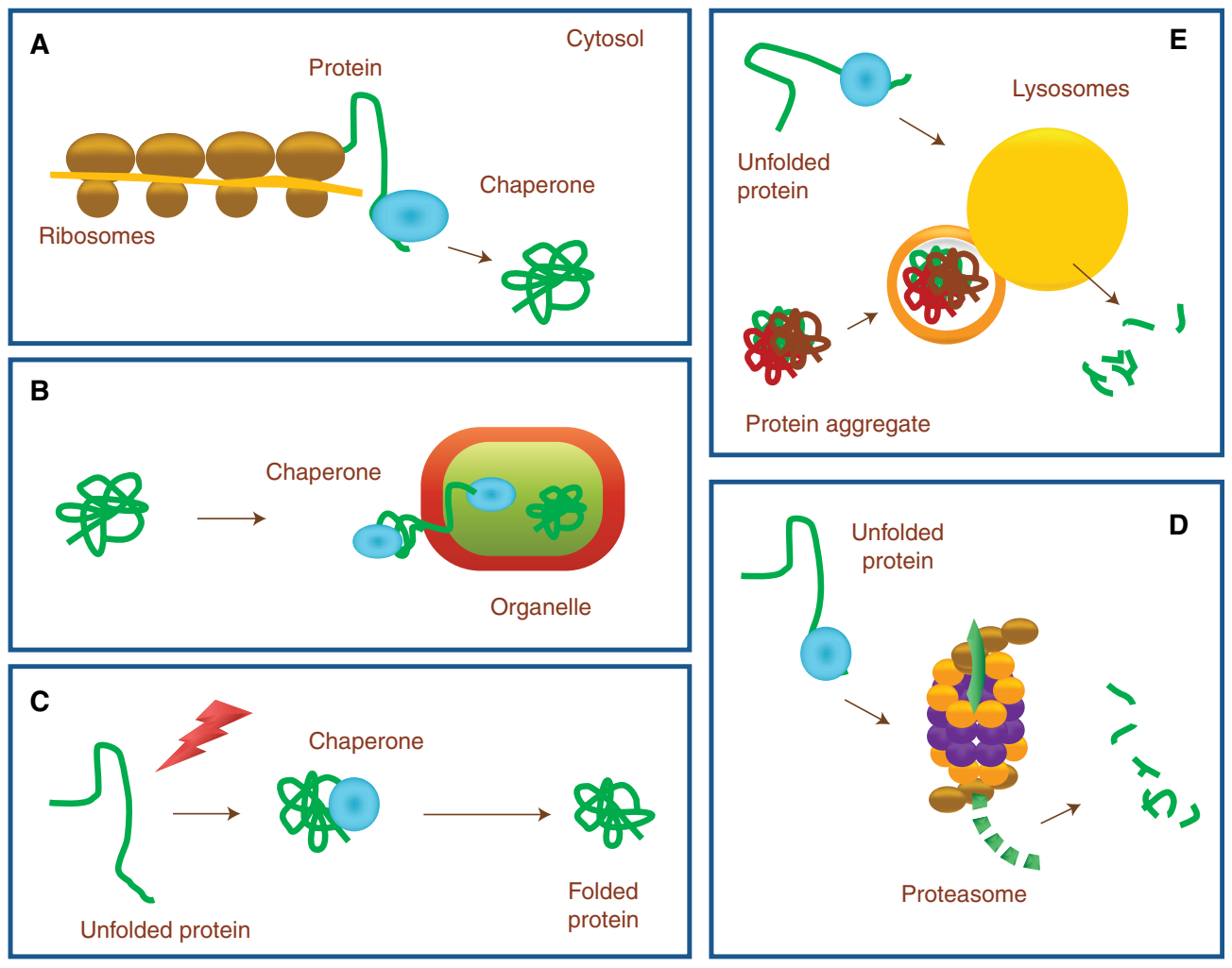

Figure 1. Coordinate action of chaperones and the proteolytic systems in quality control. Chaperones assist in the folding of de novo synthesized proteins $(A)$, unfolding and refolding of proteins as they traffic into cellular compartments $(B)$, and in the refolding of proteins when damaged by cellular aggressors $(C)$. Proteins that fail to fold can be eliminated from the cell by two proteolytic systems: autophagy $(D)$ and the ubiquitin/proteasome system $(E)$. 
Two systems share the proteolytic cellular load, the lysosomes and the UPS (Ciechanover 2005). Although these two systems bear unique properties, there are a series of essential steps and components common to both of them and required for their functions in cellular quality control. The common steps in protein degradation are: cargo selection and tagging, cargo recognition and delivery to the proteolytic machinery, degradation in the proteolytic core, and recycling of the constituent amino acids. Selection of cargo to be degraded is a prerequisite in both systems. Although for a long time it was generally accepted that cargo selection was only a prerequisite for the UPS and that degradation in the lysosomal system was in-bulk and occurred in a random manner, growing evidence support that this is not the case. In fact, as described more in detail in the following sections, molecular chaperones and other cargo-recognition molecules are often the ones determining the fate of cellular proteins and their degradation in one or the other proteolytic systems (Douglas et al. 2009). Degradation tags on the substrate proteins and the machinery required for tagging can also be shared by both the proteolytic systems (Waters et al. 2009). Following tagging, the substrate needs to be recognized by the proteolytic compartment. Association of different cargo recognition molecules with the shared proteolytic machinery, either the lysosomal compartment or the proteolytic core in the UPS, allows for variants inside each of the two proteolytic systems dedicated for the degradation of particular subsets of proteins and organelles. Both systems require catalytic activities capable of breaking the peptide bonds between amino acids. Multiple proteases with different specificity constitute the proteolytic machinery of the lysosomal system, whereas a single protease, the 20S proteasome, bearing at least three different proteolytic activities is responsible for protein breakdown in the UPS. In both systems degradation is attained in a confined compartment, the lumen of the lysosome or the catalytic chamber of the proteasome, which prevents nonspecific associations of other cellular proteins to the hydrophobic patches of amino acids that become exposed as the substrate proteins unfold and undergo degradation.

Intracellular degradation is often the most efficient mechanism to prevent toxicity associated with the accumulation of conformationally altered proteins without affecting the cellular reserves of amino acids (Goldberg 2003; Mizushima 2005). Cells can elicit alternative mechanisms when the load of proteins destined for degradation surpasses the activity of the proteolytic systems or when there is a primary failure in the functions of these systems. For example, formation of large protein inclusions has been proposed to be used by cells in certain instances to protect themselves from the toxic effect associated to oligomeric irreversible species of pathogenic proteins (Cohen and Dillin 2008). Secretion of the toxic protein products to the extracellular media is also used as a mechanism of cellular defense against proteotoxicity. Extracellular proteases can take care of the secreted products up to some extent, beyond which antitoxic aggregation mechanisms, similar to the ones described inside cells, result in the formation of protein inclusions or plaques in the extracellular media.

\section{AUTOPHAGY}

The degradation of intracellular components of any kind inside lysosomes is generically defined as autophagy, or self-eating (Mizushima et al. 2008). The essential component of this proteolytic system are the lysosomes, single membrane vesicles that contain in their lumen the larger variety of cellular hydrolases including proteases, lipases, glycosidases, and nucleotidases (De Duve and Wattiaux 1966). Common to these hydrolases is the fact that they all reach their higher enzymatic activity at the acidic $\mathrm{pH}$ of the lysosomal lumen. An ATP-dependent proton pump at the lysosomal membrane is responsible for the acidification of this organelle. The low lysosomal $\mathrm{pH}$ has been proposed to also facilitate partial unfolding of the substrate proteins allowing endoproteases to gain access to internal peptide bonds. Degradation in the lysosome is highly processive as it results from the combined action of endo- and exoproteases 
E. Wong and A.M. Cuervo

leading to conversion of proteins into small di- and tri-peptides and free amino acids that are released into the cytosol through permeases at the lysosomal membrane (Maggi and Hart 1973).

\section{Autophagic Pathways: Characteristics and Molecular Dissection}

The lysosome is the catalytic component of the autophagic system and consequently all cargo is delivered to this compartment for degradation. Cargo recognition and delivery occurs by different mechanisms depending on the type of cargo and the cellular conditions, giving rise to different modalities of autophagy (Mizushima et al. 2008; Yang and Klionsky 2009). The best characterized in mammalian cells are: macroautophagy, microautophagy, and chaperone-mediated autophagy (CMA) (Fig. 2). Variants of each of this type of autophagy have been described and named to indicate the cargo preferentially degraded: mitophagy (autophagy of mitochondria), pexophagy (autophagy of peroxisomes), lipophagy (autophagy of lipid droplets), and aggregophagy (autophagy of aggregates). A dedicated subset of cargo recognition molecules is involved in each of this autophagic variants, but the basic mechanisms and essential gene products are shared with the general forms of autophagy (Klionsky et al. 2003).

Only proteins can be delivered to lysosomes via CMA (Cuervo 2010), whereas macro- and microautophagy participate in the degradation of both proteins and organelles (Yang and

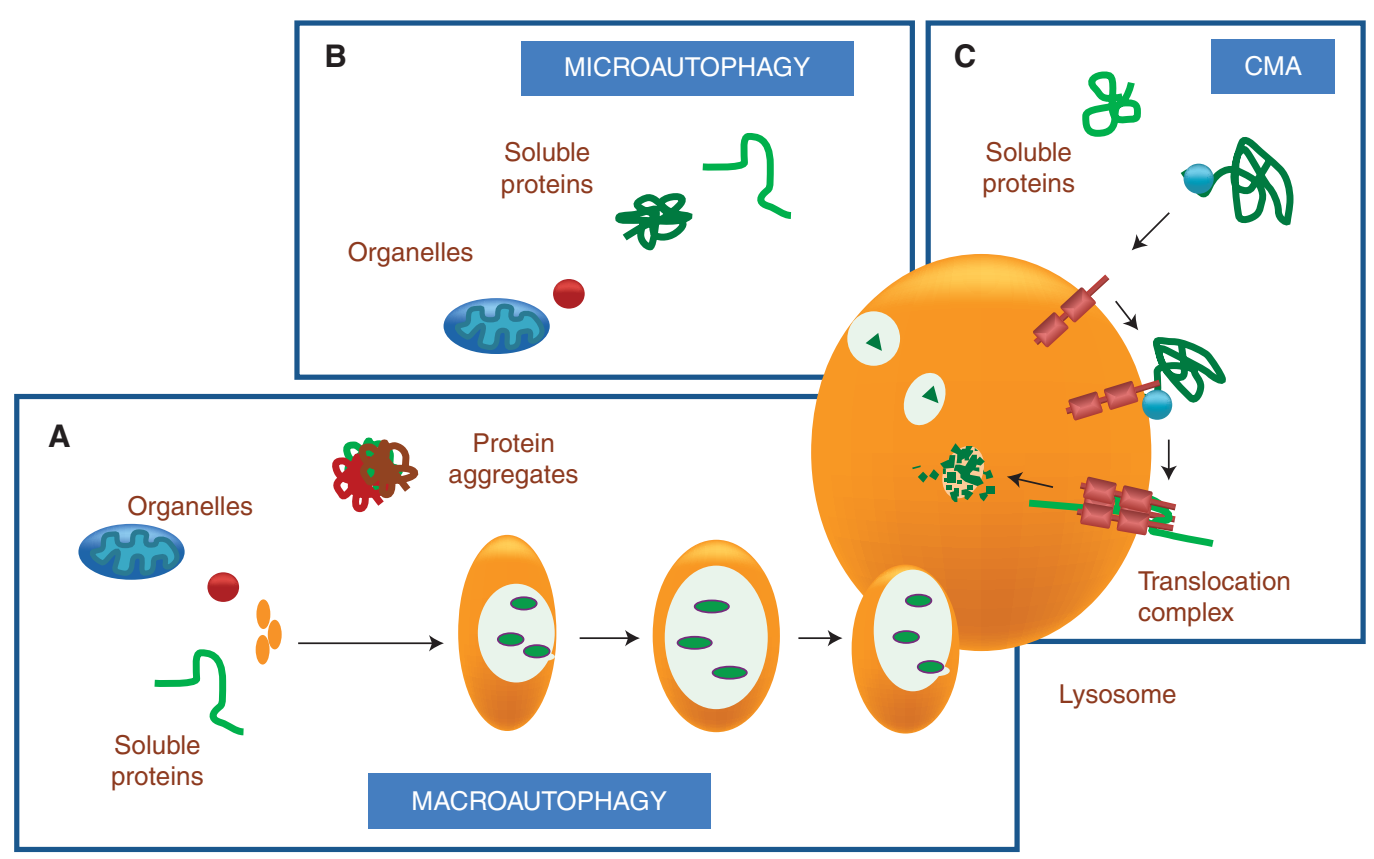

Figure 2. Autophagic pathways. Cytosolic proteins can reach the lysosomal lumen for degradation via autophagy through three different mechanisms. (A) In macroautophagy, a whole region of the cytosol is sequestered into a double membrane vesicle that fuses with lysosomes for cargo delivery. (B) In microautophagy, the lysosomal membrane invaginates to trap regions of the cytosol that are internalized into the lysosomal lumen as single membrane vesicles. $(C)$ In chaperone-mediated autophagy, a targeting motif in the substrate proteins is recognized by a cytosolic chaperone that delivers it to the surface of the lysosome. Once there, the substrate protein binds to a lysosomal receptor that multimerizes to form a translocation complex. A luminal chaperone mediates the translocation of the substrate protein into the lumen where it is rapidly degraded. 
Klionsky 2009). CMA and macroautophagy were initially described as stress-induced forms of autophagy, but recent studies support the coexistence of basal activity of both autophagic pathways in most cell types. Selectivity in cargo recognition, originally only attributed to CMA, has also been shown for the other autophagic pathways (Noda et al. 2008; Lamark et al. 2009; Tolkovsky 2009).

In macroautophagy, cytosolic cargo is sequestered inside a de novo formed double membrane vesicle or autophagosome that then fuses with late endosomes or lysosomes (Yang and Klionsky 2009) (Fig. 2). Mixing of the luminal content of autophagosomes and lysosomes allows lysosomal hydrolases to gain access to the sequestered cytosolic cargo and initiate its degradation. Degradation of cargo progresses in this mix compartment (autophagolysosome) until returning to the enzymatic enrichment characteristic of a secondary lysosome. Although macroautophagy was described almost in parallel to the discovery of the lysosome (Deter et al. 1967), it is only recently, through yeast genetic screenings, that the molecular components that participate in this process have been identified and characterized. About 35 genes, generically known as autophagy-related genes or ATG, have been shown to participate in macroautophagy (Klionsky et al. 2003). Their protein products, or Atg proteins, organize into functional complexes that regulate each of the steps of macroautophagy. Formation of the limiting membrane of the autophagosome initiates by the recruitment of different autophagic complexes to specific regions of intracellular membranes (Mizushima et al. 1998; Mizushima et al. 2002). The endoplasmic reticulum, mitochondria, and the plasma membrane are confirmed sites of autophagosome formation (Axe et al. 2008; Hailey et al. 2010; Ravikumar et al. 2010). Preferential formation from one or another site may depend on the stimulus that activates autophagy and could determine the type of cargo sequestered inside the autophagosome. In the three sites for autophagosome formation, specific Atgs act as platform of assembly of other Atgs to the membrane.
Complexes recruited to the membrane include: (1) Atgs involved in two conjugation cascades, a protein-protein conjugation and a protein-lipid conjugation system, along with the enzymes that catalyze these conjugation events (Mizushima et al. 1998); (2) a beclin-containing kinase complex that brings along a phosphatidylinositol 3 kinase type III responsible for the enrichment in this lipid modification on the surface of the membrane that will give rise to the autophagosome (Itakura et al. 2008); and (3) a second kinase complex, that on activation of autophagy dissociates from the negative regulator of autophagy, mTOR, and mobilizes to the region of autophagosome formation (Hosokawa et al. 2009). Although self-phosphorylation of this complex has been reported, other targets of the kinase activity of this second complex are currently under investigation. Atg complexes do not assemble irreversibly at the site of autophagosome formation but rather most of them undergo continuous shuttling from other intracellular membranes to these regions (Suzuki and Ohsumi 2010). This shuttling is believed to contribute the lipids required for the elongation of the limiting membrane that then seals around the cargo through mechanisms still poorly characterized. Fusion of the autophagosome with lysosomes involves microtubules, and proteins in the membranes of both autophagosomes and lysosomes that contribute to modulate the fusion process and the mixing of content between both compartments. Most forms of autophagy are subjected to the negative regulatory effect of one of the major kinases in the cell, mTOR, and the components associated to this kinase as part of the TORC1 complex (Meijer and Codogno 2004). The diverse array of cellular and extracellular cues sensed by mTOR, insulin, amino acids, ATP, hormones, glucose, and stress factors, matches with the stimuli that modulate autophagic activity in cells.

Autophagosomes and autophagolysosomes are the morphological signature of macroautophagy and have been used as direct indicators of the changes in the activity of this autophagic pathway in cells and tissues. The identification of the proteins that participate in the formation 
and cellular dynamics of these vesicles has now allowed tracking these compartments in realtime by using tagged forms of these proteins (Yang and Klionsky 2009). Furthermore, overexpression and knock-down or knock-out of essential Atgs has provided a better understanding of the cellular consequences of changes in macroautophagic activity under physiological and pathological conditions (Komatsu 2005; Hara et al. 2006).

Less information is currently available about microautophagy, a form of autophagy that also involves sequestration of whole regions of the cytosol but directly by the lysosomal membrane (Ahlberg and Glaumann 1985) (Fig. 2). This process has been better characterized in yeast where a subset of gene products have been shown to contribute to the formation of the membrane projections from the surface of the vacuole (the equivalent of the lysosome in yeast) that sequester soluble proteins and organelles and internalize them inside small vesicles in the lumen of the vacuole (Tuttle and Dunn 1995; Dubouloz et al. 2005). Although most microautophagy degradation occurs probably "in bulk," selective removal of certain organelles has also been described (i.e., micropexophagy for the selective degradation of peroxisomes) (Sakai et al. 1998). The absence of mammalian homologs for the microautophagy yeast genes has made it difficult in gaining a better understanding of the pathophysiology of this process.

In mammalian cells a third type of autophagy selective for the degradation of a subset of cytosolic proteins has been named as chaperone-mediated autophagy (CMA) (Dice 2007; Cuervo 2010) (Fig. 2). This process requires the recognition of the targeting motif in the substrate protein by a cytosolic chaperone and its subsequent targeting to the surface of the lysosome where it binds to a membrane receptor protein (Cuervo and Dice 1996). Internalization of the substrate into the lysosomal lumen is mediated by a lysosome resident protein and, in contrast with the other two autophagic processes, it requires complete unfolding of the substrate protein before translocation (Salvador et al. 2000). The limiting step in this form of autophagy is the binding of the substrates to the lysosomal membrane receptor. On substrate binding, the receptor protein multimerizes to form a complex required for substrate translocation (Bandyopadhyay et al. 2008). Specific membrane proteins regulate the assembly and disassembly of this receptor and contribute to modulate the activity of this pathway (Bandhyopadhyay et al. 2010). A certain level of basal CMA is detectable in all cells, but this pathway is maximally activated in response to stress (Cuervo and Dice 1996; Dice 2007).

\section{Physiological Functions of Autophagy}

In recent years, a growing number of functions have been attributed to autophagy, but almost all of them can be included in one of the following four categories: quality control, cellular source of energy, cell and tissue remodeling, and cellular defense (Mizushima et al. 2008). The ability of different autophagic pathways to break down intracellular components (e.g., proteins, lipids, sugars, and nucleic acids) and recycle their constituent elements back to the cytosol makes it an ideal mechanism to supply cells with this elements when nutrients are scarce (Mizushima 2005). Both macroautophagy and CMA are maximally up-regulated in response to nutrient deprivation. Autophagy, in particular macroautophagy, also contributes to the elimination of large portions of cytosol, organelles, plasma membrane, or even cellular corpses in processes such as cellular differentiation, tissue remodeling, and embryogenesis (Levine and Klionsky 2004). Similarly, pathogens (e.g., bacteria, parasites, and viruses) that reach the cellular cytosol through phagocytosis or directly across the plasma membrane can be successfully eliminated by the autophagic systems, acting thus at the forefront of cellular defense (Deretic 2009).

Of relevance to this article is the important role of the autophagic system in cellular quality control (Fig. 2). The fact that altered organelles and cytosolic components are eliminated in lysosomes has been known since the identification of this organelle. However, it has only been recently that the contribution of this "cleaning" 
function to the maintenance of cellular homeostasis has been conclusively documented. Cells knocked down for different essential autophagic genes show accumulation of abnormal organelles and protein deposits in their cytosol, even when maintained in the absence of any other aggravating factor (Ravikumar et al. 2002; Iwata et al. 2005). Similar results have been observed in whole animal knockout for autophagy genes in a specific tissue (Komatsu 2005; Hara et al. 2006). Although the phenotype of these animals depends on the affected organ or tissue, the changes at the cellular level are the same for all tissues. These studies support that normal autophagic activity is essential for the maintenance of cellular homeostasis through the continuous turnover of organelles and of damaged or altered proteins.

Interestingly, the protein inclusions observed in the animal models with impaired autophagy are often enriched in ubiquitin, a small protein that, as described in detail in the following sections, can be used for tagging of cytosolic proteins for degradation through the UPS. It is still controversial whether the accumulation of ubiquitinated proteins in aggregates in macroautophagy-incompetent cells reflects that aggregates are normally degraded by this pathway, or if it is possible that soluble ubiquitinated proteins are also substrate for macroautophagy (Ferguson et al. 2009; Korolchuk et al. 2009). The degradation of aggregated proteins by macroautophagy has been extensively reported and it is currently referred to as aggregophagy (Ravikumar et al. 2002; Iwata et al. 2005). The presence of ubiquitin molecules on the surface of these protein inclusions has been shown to facilitate the recruitment of components of the macroautophagic machinery to these aggregates leading to the in situ formation of the autophagosome. Selective degradation of the aggregates is also mediated by cargo recognition proteins such as p62 or NBR1, which can interact directly with ubiquitin moieties and with LC3, one of the essential autophagy proteins that associate with the autophagosome membrane (Lamark et al. 2009). However, although all these molecules are necessary for autophagy of aggregates they may not be sufficient, because aggregates of certain pathogenic proteins are positive for ubiquitin and the cargo recognition molecules and still fail to be recognized by the autophagic system (Wong et al. 2008). It is possible that additional molecules or posttranslational modifications in the aggregated proteins are required for autophagy recognition.

Compromised CMA also leads to alterations in cellular homeostasis. Studies in cells knocked down for the lysosomal receptor of this pathway show accumulation of cytosolic proteins, protein aggregation, and increased sensitivity to different stressors (Fig. 2). In contrast to macroautophagy-impaired cells, the organelle compromise in these cells is minimal and mainly secondary to the accumulation of the protein products (Massey et al. 2006).

\section{Pathophysiology of the Quality Control Through Autophagy}

In light of the important role that the autophagic system plays under normal physiological conditions, it is not surprising that alterations of autophagy have been identified in many human pathologies. In fact, dysfunctional autophagy underlies the basis of a growing list of protein conformational disorders (Wong and Cuervo 2010). The first connection between these disorders and the autophagic system originated from studies showing up-regulated macroautophagic activity in cells expressing pathogenic forms of different proteins associated to disorders such as Parkinson's or Huntington's disease (Ravikumar et al. 2002; Iwata et al. 2005). This increase in macroautophagy seemed of protective nature because when precluded, cellular viability was often compromised. These observations along with the previously described degradation of protein aggregates by macroautophagy lead to the postulation that enhancement of macroautophagy could be an effective intervention in these disorders. In fact, studies in fly and mouse models of Huntington's disease revealed that chemical up-regulation of macroautophagy in these models slowed down disease progression by reducing proteotoxicity and increasing cellular viability (Ravikumar et al. 2004). At the same 


\section{E. Wong and A.M. Cuervo}

time, these studies also suggested that compromised macroautophagy could underlie the pathogenesis of some of these disorders, something that has now been extensively documented. Reduced macroautophagic activity has been reported in Parkinson's disease, Huntington's disease, Alzheimer's disease, polyglutamine diseases, amyotrophic lateral sclerosis and prion diseases, among others (Sarkar et al. 2009) (Fig. 3). However, interestingly, a developing theme is that the autophagic defect is not uniform across all these diseases. Alterations in autophagy in these disorders spread across problems in autophagosome formation, cargo recognition, autophagosome mobilization toward lysosomes, autophagosome/lysosome fusion or in the degradation of the autophagic cargo once delivered to lysosomes (Wong and Cuervo 2010). Furthermore, in some instances the macroautophagic defect is primarily caused by alteration in one of the autophagy components, whereas in other instances the autophagic failure is secondary to alterations in the other quality control mechanisms. For example, defective autophagy in some familial forms of Alzheimer's disease carrying mutations in presenilin 1 , is a consequence of a primary defect in lysosomal acidification (Lee et al. 2010). In contrast, the initial up-regulation of the autophagic system in some familial forms of Parkinson's disease is likely a compensatory response for the failure in the ubiquitin/proteasome system and CMA in the affected cells (Stefanis et al. 2001; Cuervo et al. 2004).

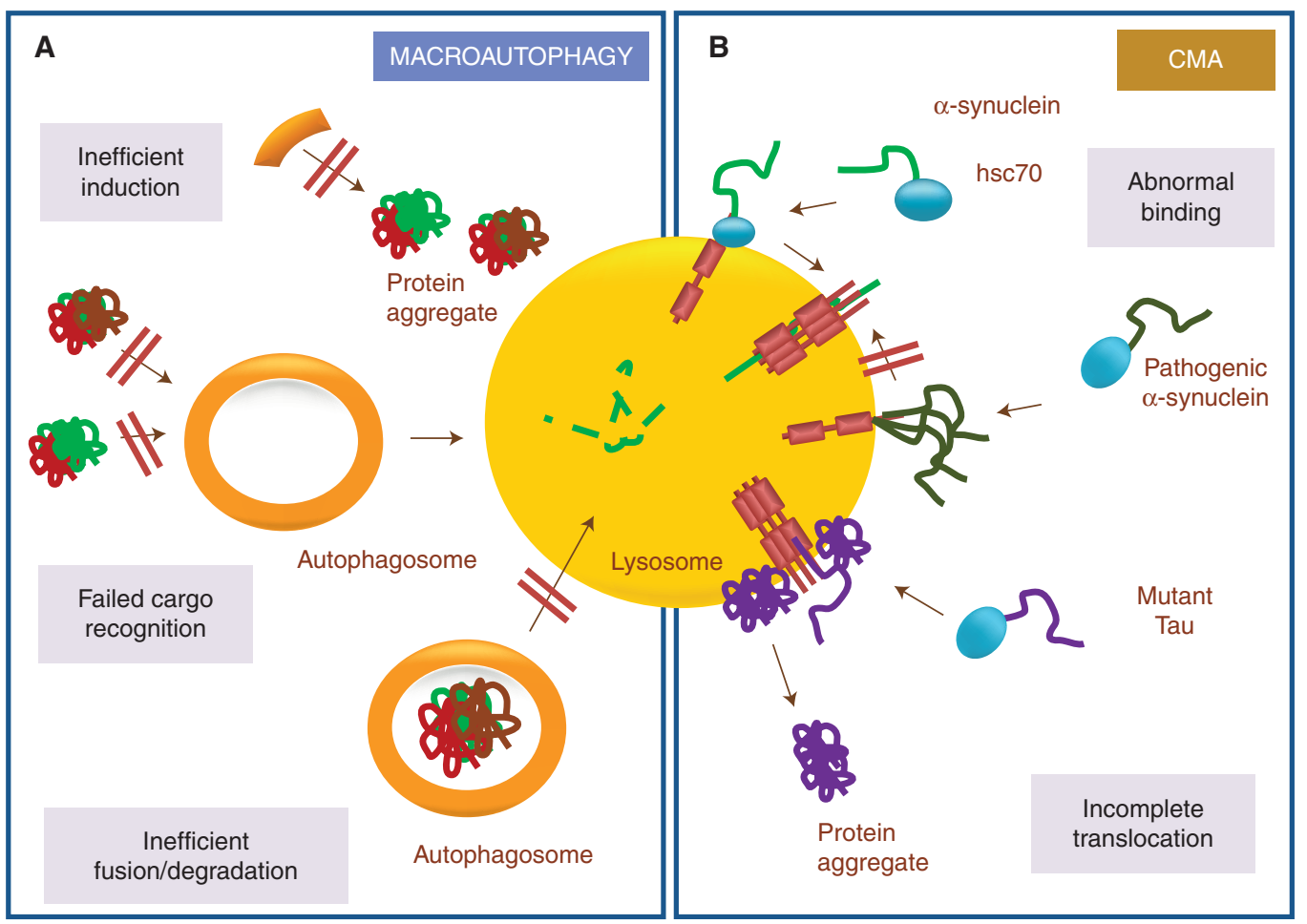

Figure 3. The autophagic system in quality control. Autophagy contributes to the removal of both soluble cytosolic proteins and proteins organized into irreversible complexes or aggregates. Impairment of the autophagic system leads to the accumulation of damaged proteins in the form of protein inclusions. Failure of both macroautophagy $(A)$ and chaperone-mediated autophagy $(B)$ has been described to contribute to pathogenesis in different protein conformational disorders. Some of the steps described to be affected in each of the autophagic pathways are illustrated here. 
Compromised CMA has also been linked to neurodegenerative disorders (Fig. 3). $\alpha$-Synuclein, the protein that accumulates in the protein inclusions observed in the affected neurons in Parkinson's disease (PD), undergoes degradation via CMA. In contrast, mutant forms of this protein and pathogenic variants of the wild type protein are targeted to lysosomes and bind to the lysosomal receptor but fail to be translocated (Cuervo et al. 2004; Martinez-Vicente et al. 2008). Furthermore, because their interaction with the lysosomal membrane displays an unusual high affinity, degradation of other cytosolic substrates for this pathway is also compromised. Impaired CMA contributes thus to altered homeostasis in the affected cells, enhanced sensitivity to stressors, and could lead to cellular death. Abnormal interaction with CMA components has also been described recently for UCH-L1, another PD-related protein (Kabuta and Wada 2008). The compromise in CMA is not limited to $\mathrm{PD}$, as recent studies have revealed similar blockage of this pathway by certain mutant forms of Tau, the protein responsible for cellular toxicity in some tauopathies (Wang et al. 2009). It is thus likely that CMA could also be the target of other pathogenic proteins associated to other conformational protein disorders.

\section{Chemical Modulation of Autophagic Clearance}

The promising results obtained on up-regulation of macroautophagy in the models of Huntington's disease (HD) (Ravikumar et al. 2004) has generated considerable interest in the possibility of using modulators of autophagy with therapeutic purposes in protein conformational disorders. So far, the amount of chemicals proven to enhance autophagy is still rather limited. Inhibition of mTOR by rapamycin has been shown effective as macroautophagic activator, but the large number of other cellular processes controlled by this cellular kinase limits its clinical applicability (Ravikumar et al. 2004). Regulation of macroautophagy by mechanisms independent of mTOR has also been reported and seems the basis for the stimulatory effect of lithium on this process (Sarkar et al. 2005). Ongoing small molecule screenings should soon render a battery of compounds that could be applied to enhance macroautophagic activity in vivo. However, one of the limitations of most of these compounds is that they all act on early steps of macroautophagy enhancing autophagosome formation, but will not have a beneficial effect in those pathological conditions in which the autophagic defect is in steps past autophagosome formation. In fact, up-regulation of autophagy could even be detrimental in those pathologies with reduced clearance of autophagosomes. Customized interventions, aimed at repairing the specific autophagic defect in each of the different conformational disorders are a more promising future possibility.

Only genetic manipulations have been used so far in animal models to enhance CMA (Zhang and Cuervo 2008). A small-scale screening of a dozen of compounds revealed enhanced CMA in cells treated with some of them (Finn et al. 2005). However, because the targets of those drugs were very general and a link between those targets and CMA has not yet been established, it is not possible to determine whether their effect on CMA is direct or secondary to other cellular effects of these drugs.

\section{THE UBIQUITIN/PROTEASOME SYSTEM}

The UPS is the major pathway responsible for the highly regulated extralysosomal degradation of cytosolic proteins and of proteins residing in the nucleus and endoplasmic reticulum in eukaryotic cells (Coux et al. 1996; Baumeister et al. 1998). The UPS degrades mostly shortlived proteins through a multistep process that requires the tagging activity of a sophisticated system. The tagging molecule is a small protein, ubiquitin, that once covalently linked to proteins, earmarks them for destruction by the $26 \mathrm{~S}$ proteasome, a highly conserved multicatalytic ATP-dependent protease complex (Fig. 4). The rapid, precise and timely processing of a vast extent of cellular proteins by the UPS allows tight control of critical cellular 

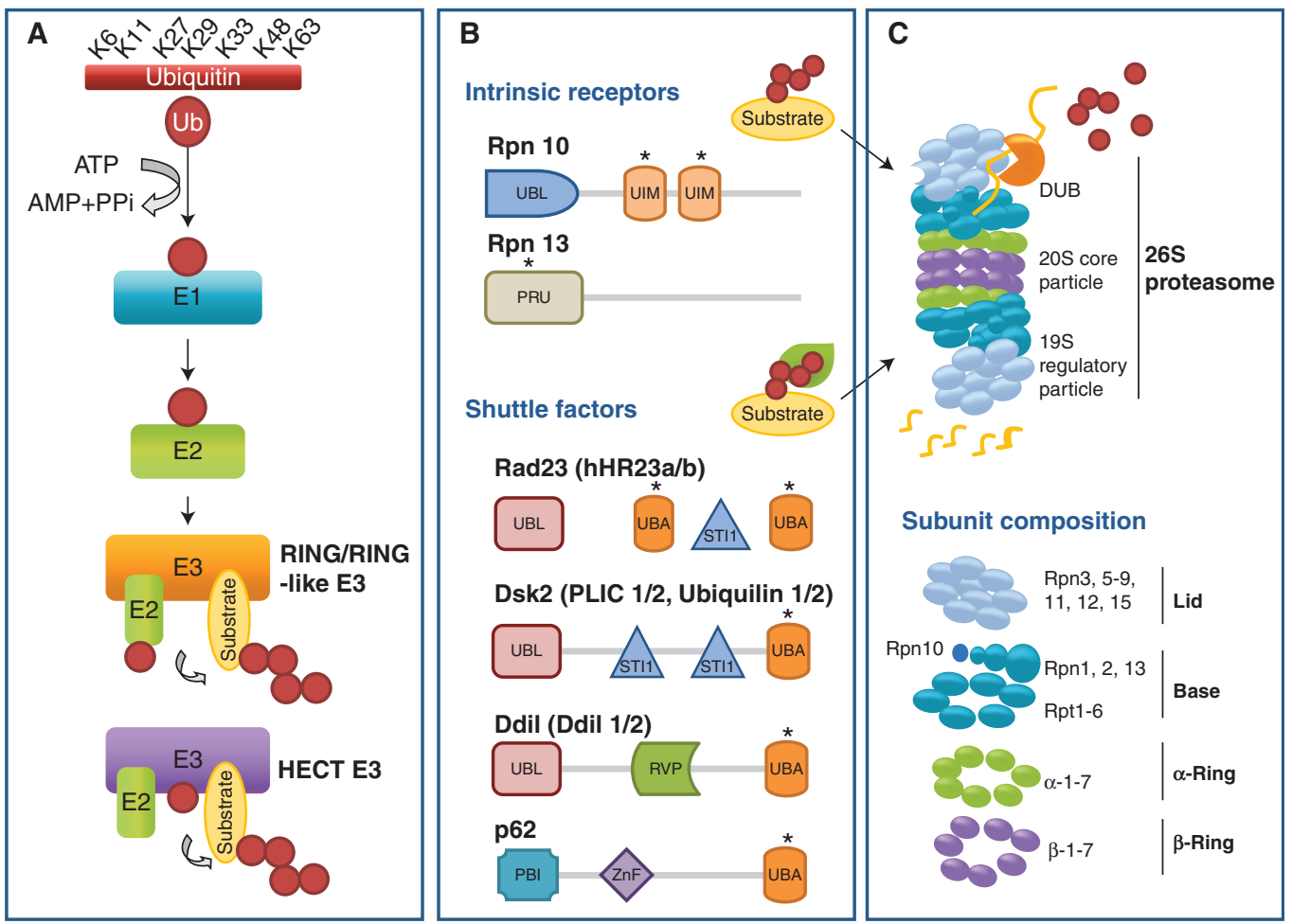

Figure 4. Components of the ubiquitin/proteasome system. Substrates destined for proteasomal elimination are tagged with polymers of ubiquitin (Ub) through repeated sequential reactions catalyzed by ubiquitin activating (E1), conjugated (E2), and ligating (E3) enzymes ( $A$ ) RING/RING-like E3 catalyzes the transfer of Ub directly from E2 to substrate whereas HECT E3 accepts activated Ub from E2 before transferring it to the substrate. Ubiquitinated substrates either bind directly to the ubiquitin receptors in the proteasome regulatory particle or shuttle to the proteasome by shuttle factors $(B)^{*}$ indicates domain binding polyubiquitin chain. Binding of substrate is followed by protein unfolding by the six ATPases forming the base of $19 \mathrm{~S}$ regulatory particle, removal of polyubiquitin chain by deubiquitinating enzymes (DUBs) to regenerate free Ub, and translocation of the unfolded protein into the core proteolytic chamber, where it is cleaved into short peptides (C).

functions such as DNA repair, cell cycle progression, development, apoptosis, gene transcription, signal transduction, senescence, immune response, metabolism, and protein quality control.

\section{Ubiquitin-Conjugation: The "Kiss of Death" for Cellular Proteins}

Most substrate proteins are targeted to the $26 \mathrm{~S}$ proteasome by the covalent attachment of multiple ubiquitin proteins to the substrates in a process known as ubiquitination. Ubiquitin is a small $(8.5 \mathrm{kDa})$ globular protein that is extremely stable and highly conserved from yeast to mammals. In most cases, the first ubiquitin is attached via its carboxy-terminal glycine residue to the $\varepsilon$-amino group of a lysine residue in the substrate to generate an isopeptide bond. In substrate proteins without lysine residues, ubiquitin can be conjugated to their amino terminus, forming a linear peptide bond (aminoterminal ubiquitination) (Ben-Saadon et al. 2006). The conjugation of ubiquitin to a substrate is orchestrated by the actions of three enzymes (Hershko and Ciechanover 1998). In an ATP-consuming first step, ubiquitin is bound by a high-energy thioester bond to E1 
(ubiquitin-activating enzyme), becoming thus activated. Subsequently, ubiquitin is transferred to the active site of E2 (ubiquitin-conjugating enzyme). In the final step, E3 (ubiquitin-ligase enzyme) catalyzes the transfer of ubiquitin to the substrate protein destined for degradation (Fig. 4). Because of the presence of internal lysine residues, ubiquitin can be repeatedly attached to itself through repeated actions of the conjugating enzyme cascade to form polymeric ubiquitin chains.

The selection of substrates for UPS degradation is governed by the specificity of E3 enzymes through two possible strategies. E3 enzymes can recognize and bind a degradative signal or "degron" in the sequence of the unstable protein. For example, the presence of either basic or hydrophobic residues at the amino-terminal of a protein ( $\mathrm{N}$-degrons) tends to destabilize it and facilitates its recognition by E3 (Ravid and Hochstrasser 2008). The specificity of other E3 ligases such as CHIP (carboxyl terminus of Hsc70-interacting protein) can be modulated through its interaction with cytosolic chaperones such as Hsp70 and Hsp90. CHIP uses these two chaperones as a recognition subunit of unstructured regions in client proteins $(\mathrm{Mu}-$ rata et al. 2001). In addition, CHIP can also bind nonnative proteins without Hsp70 or Hsp90, suggesting that there are multiple ways by which substrates can be recognized by this E3 and likely other E3 enzymes in general (Rosser et al. 2007). Conceivably, more strategies of substrate selection may exist, judging from the multiplicity of ubiquitin-related enzymes that includes two E1 enzymes, around one hundred E2 enzymes, and more than a thousand E3 enzymes (Staub and Rotin 2006). As indicated in previous sections, recent studies support a broader role of ubiquitin-conjugation in cellular quality control, because ubiquitin tagging is no longer limited to targeted degradation by the UPS, but instead it also participates in selective autophagic degradation.

It is noteworthy that some substrate proteins do not require ubiquitination to be degraded by the proteasome, although the relevance of this process in vivo is still unclear (Murakami et al. 1992).

\section{The Ubiquitination Language}

The way in which ubiquitin is conjugated to the substrates (ubiquitin linkages) constitutes another layer of control in the degradation of substrates by the UPS. Similar to phosphorylation, ubiquitination is a reversible modification that is rapid, specific, and diverse. Besides UPS-mediated degradation, ubiquitin also participates in a broad array of proteasomeindependent cellular functions (Fig. 5). The versatility of the ubiquitination is endowed by the presence of seven lysine residues in ubiquitin at positions $6,11,27,29,33,48$, and 63 , which can each serve as acceptors of other ubiquitin molecules. Quantitative proteomics in yeast have revealed the occurrence of the seven ubiquitin linkages although in varying abundance (Xu et al. 2009). K48 and K11 linkages are the most abundant ubiquitin chain types in yeast followed by K63. K6, K27, K29, and K33. This gives rise to differently linked polyubiquitin chains with distinct quaternary structures and topologies (Ikeda and Dikic 2008) (Fig. 5). The different topologies of the ubiquitin chains serve as distinct binding surfaces for different classes of ubiquitin-binding proteins (Hicke et al. 2005; Raasi et al. 2005; Varadan et al. 2005). Besides homogenous polyubiquitin chains, cells can also generate heterogeneous chains whereby ubiquitin molecules are linked to different internal lysine residues within a single chain or in which more than one ubiquitin molecule is attached to a single ubiquitin forming branched chain (BenSaadon et al. 2006; Kirkpatrick et al. 2006; Kim et al. 2008). Further adding to the complexity, the polyubiquitin chains can be of varying lengths and substrate proteins can also be tagged with a single ubiquitin on a single lysine residue (monoubiquitination) or on multiple lysine residues (multimonoubiquitination).

Different modes of ubiquitination determine different cellular fates of a protein (Fig. $5)$. In the case of proteasomal degradation, proteins bearing chains of at least four ubiquitin molecules are the preferred substrates of the 26S proteasome (Jentsch and Schlenker 1995; Hochstrasser 1996; Thrower et al. 2000). 


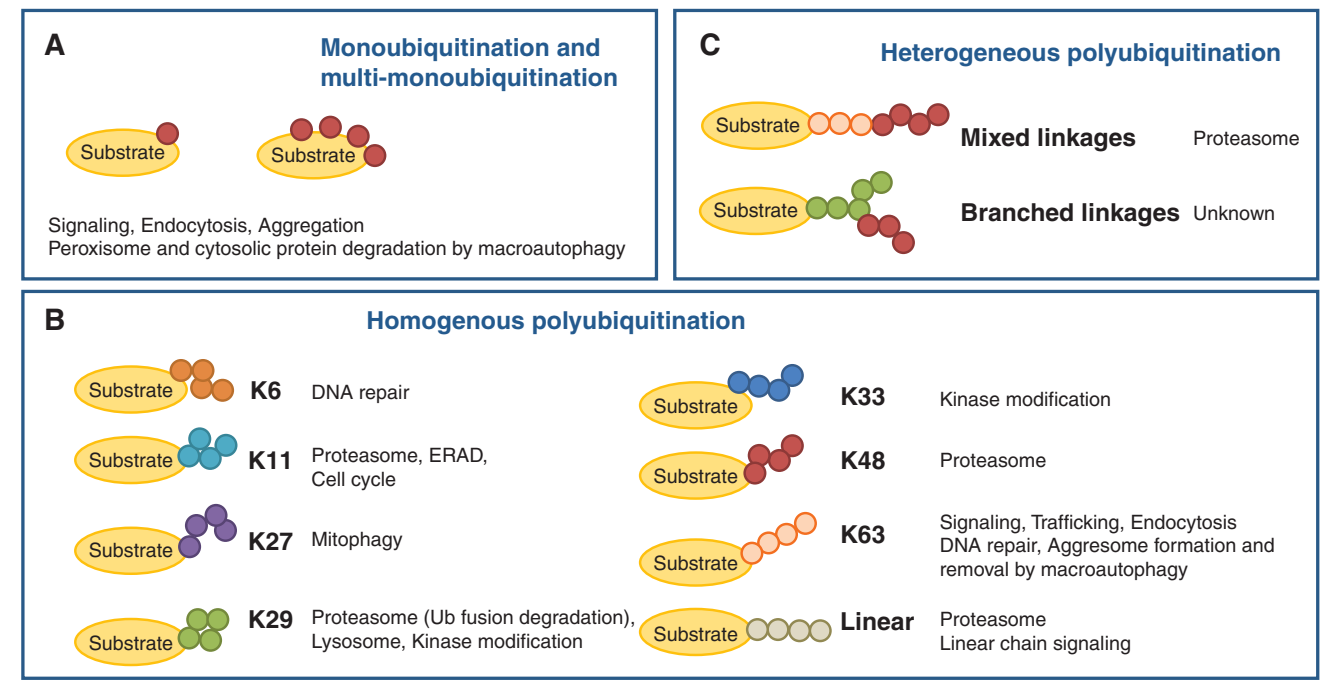

Figure 5 . The ubiquitin code. The ubiquitin molecule can be attached to a single site $(A)$ or multisites $(B-C)$ on a substrate to yield mono- and multi-ubiquitination respectively. In addition, the ubiquitin sequence contains seven lysine residues that can support the assembly of polyubiquitin of different chain topologies. The plethora of ubiquitin linkages makes ubiquitination a highly versatile modification that serves diverse roles in the cell. Heterogeneous polyubiquitination $(C)$ occurs when a ubiquitin chain has alternating linkage types (mixed linkages) or when a single ubiquitin is extended at two or more lysine residues (branched linkages).

Regarding the type of linkage, K48 has been identified as the canonical signal that targets proteins to the proteasome for degradation, but K11 linkage can also serve as a potent proteasomal degradation signal (Baboshina and Haas 1996; Kirkpatrick et al. 2006; Jin et al. 2008; Kim et al. 2008; Xu et al. 2009), particularly on cell cycle regulatory proteins (Jin et al. 2008) and on endoplasmic reticulum substrates (Xu et al. 2009). K29 linkage has recently been associated with the degradation of amino-terminal ubiquitinated substrates (Johnson et al. 1995; Koegl et al. 1999). Although the K63 linkage is typically implicated in proteasome-independent functions, recent studies support that this linkage can also target some substrates for degradation by the proteasome, at least in vitro (Crosas et al. 2006; Kirkpatrick et al. 2006; Kim et al. 2007). Interestingly, K29 and K63 linkages have been recently implicated in substrate targeting for degradation through autophagy (Chastagner et al. 2008; Tan et al. 2008b).

The proteasome can process both homogenous and heterogeneous polyubiquitin chains formed by the sequential action of different E2 enzymes (Kirkpatrick et al. 2006; Jin et al. 2008). The different types of linkage not only dictate the ability of the regulatory subunits of the $26 \mathrm{~S}$ proteasome to recognize the substrate protein, but they also affect their kinetics of degradation in this protease complex. K48 ubiquitinated substrates are the most rapidly degraded by purified proteasomes proving that this linkage is still the most efficient targeting signal for proteasomal degradation (Xu et al. 2009). In contrast, branched polyubiquitin chains are not processed efficiently by the proteasome (Kim et al. 2007), hence calling into question the in vivo role of these branched chains. On the other side of the scale, some of the linkages may exert inhibitory functions over the proteasome (i.e., K6 linkage inhibits proteasomal degradation (Shang et al. 2005).

\section{Decoding Ubiquitination at the Proteasome}

Once ubiquitin-tagged, the substrate proteins are routed to the proteasome for degradation. Most substrates dock at the proteasome via 
binding to specific ubiquitin receptors, which include the stable subunits of the proteasome, Rpn10 and Rpn13, and several transiently associated shuttle factors such as Rad23, Dsk2, Ddil, and p62 (Finley 2009) (Fig. 4). Direct docking of ubiquitinated substrates to the proteasome is possible via binding to Rpn 10 and Rpn13 whereas remote substrates can be captured and escorted to the proteasome by the shuttle factors. The substrate binds to the ubiquitin-associated (UBA) domain in the shuttle factor, which in turn binds to the proteasome through its ubiquitin-like (UBL) domain. The UBA domains in these ubiquitin receptors may have preferential affinities for different ubiquitin linkages and different chain lengths (Seibenhener et al. 2004; Raasi et al. 2005; Varadan et al. 2005; Long et al. 2008; Tan et al. 2008a). Besides ubiquitin, selectivity of UBA is also defined by determinants in the conjugated substrates (Verma et al. 2002). The shuttle factors may thus impose a hierarchical order of degradation for the different ubiquitin chains.

On binding, deubiquitinating enzymes (DUBs) mediate the disassembly of polyubiquitin chains from the captured substrates before they can gain access to the proteolytic core. DUBs provide additional regulatory control before protein degradation, and they play an important role in recycling ubiquitin and maintaining a sufficient pool of free ubiquitin in cells. Rpn11, a regulatory subunit of the proteasome, is responsible for substrate deubiquitination at the proteasome usually removing whole chains at once (Verma et al. 2002; Yao and Cohen 2002). Other DUBs can also perform deubiquitination on the substrates before the substrates are committed to degradation and become subject to the activity of Rpn11. For example, Uch37 and Ubp6 antagonize substrate breakdown by trimming the ubiquitin chains, which reduces its binding affinity to the proteasome and favors their release back to the cytosol (Lam et al. 1997; Hanna et al. 2006). Some DUBs show preference for specific ubiquitin linkages making these linkages less stable and likely reducing their chances of degradation through the proteasome (Komander et al. 2009a; Komander et al. 2009b).

\section{The 26S Proteasome}

The $26 \mathrm{~S}$ proteasome is a large $\sim 2.5 \mathrm{MDa}$ ATPdependent multisubunit protease complex that consists of two portions: the catalytic 20S core particle (CP) and the regulatory particle (RP) (Fig. 4). The activity of the 20S CP is regulated by the assembly of different RPs (19S and 11S) that dock on one or both sides of the catalytic core to form several proteasome species (Murata et al. 2001; Finley 2009). The $26 \mathrm{~S}$ proteasome, formed by the association of $20 \mathrm{~S} \mathrm{CP}$ to $19 \mathrm{~S}$ RP plays a prominent role in quality control.

The CP is a barrel-like structure formed by 28 subunits organized in two outer $\alpha$-rings and two inner $\beta$-rings, each comprising seven structurally similar $\alpha$ - and $\beta$-subunits respectively (Goldberg 2003; Pickart and Cohen 2004) (Fig. 4). The $\alpha$-rings serve as a gate for substrate entry into the proteolytic chamber formed by the $\beta$-rings, which bear caspase-like, trypsin-like, and chymotrypsin-like proteolytic activities. Proteasomes with different catalytic activities can be generated by exchanging the different proteolytic active subunits of the CP.

Because the active sites are located on the inner surface of the proteolytic chamber, the proteasomal substrates must first gain entry into this space. This event is regulated by the association of 19S RP which controls the opening and closing of the $\alpha$-rings in the 20S CP. The 19S RP consists of 19 subunits organized in a lid and a base. The base is composed of six AAA' ATPase subunits (Rpt 1-6) and four non-ATPase subunits (Rpn 1, 2, 10, and 12) (Finley 2009). The ATPase subunits provide the energy needed for deubiquitination and unfolding of the substrates, which is a prerequisite for threading through the narrow channel of the 20S CP, as well as for $\alpha$-ring gate opening. The high energy requirements of the UPS explain why conditions that promote mitochondrial dysfunction and thereby energy depletion may affect proteasome-mediated degradation. 
Pathophysiology of the Quality Control Through the Ubiquitin/Proteasome System

Malfunctioning of the UPS, which could occur at many steps of this complex degradative process, results in severe cellular alterations and, if persistent, often leads to cellular death. Part of the cellular pathology is a direct consequence of the critical cellular functions modulated by this proteolytic system, but cellular toxicity in UPS-compromised cells also arises from its role as a quality control mechanism. In this respect toxicity is not limited to the cytosol, but also to the nuclei and ER where the UPS is also critical for quality control. Proteotoxicity in the nucleus can result in alterations in the genetic material and in major changes in transcriptional activity. In the case of the ER, secretory proteins that fail to fold in this compartment can be retrotranslocated into the cytosol where the UPS accounts for their degradation. Because retrotranslocation and UPS degradation are highly coupled processes, inhibition of the UPS blocks retrotranslocation and leads to the accumulation of the unfolded proteins in the ER lumen. Although cells count on exquisite mechanisms of defense against ER stress, because of the critical role of this organelle in protein synthesis, persistent ER stress because of maintained compromise of the UPS has been shown to underlie the pathogenesis of important protein conformational disorders.

The consequences of UPS failure on cellular homeostasis have been widely analyzed through the use of potent inhibitors of the proteolytic activities of the 20S CP (Adams 2004). In fact, several of these inhibitors are currently used as antioncogenic drugs, because of the pronounced toxic effect that they exert in rapidly dividing cancer cells. One of the immediate consequences of proteasome inhibition is the cytosolic accumulation of protein inclusions enriched in ubiquitin. These inclusions, which often also contain chaperones and components of the $26 \mathrm{~S}$ proteasome, resemble those described in the affected cells in protein conformational disorders, suggesting that compromised proteasome activity could be behind the pathogenesis of these disorders. In fact, altered proteasome activity has been described in many neurodegenerative disorders, and recently genetic depletion of proteasome subunits in mouse brain has been shown to induce a full phenotype of neurodegeneration (Bedford et al. 2008).

Like autophagy, alterations in the UPS could occur at very different levels and through mechanisms unique for each disease. In some protein conformational disorders, the proteolytic core of the proteasome becomes a target for the toxic action of the pathogenic protein. For example, incubation of $26 \mathrm{~S}$ proteasomes with mutant huntingtin, tau, or $\alpha$-synclein proteins involved in common neurodegenerative disorders, has been shown to exert an inhibitory effect on this protease by directly clogging the entrance of other substrates (Keck et al. 2003; Landles and Bates 2004; Bennett et al. 2005; Betarbet et al. 2005). In other instances, components of the UPS are down-regulated or mutated in the affected cells. For example, down-regulated expression of catalytic and regulatory proteasome subunits has been described in different tissues of aging organism (Keller et al. 2002; Chondrogianni and Gonos 2008). Likewise, genes mutated in familial forms of PD, include members of the UPS such as the E3 ligase parkin and the ubiquitin carboxyl-terminal hydrolase (UCHL1) (Alves et al. 2008; Yang 2009). The functional consequences of these mutations on the UPS activity are currently under investigation. In addition, similar to any other cellular component, the UPS can also be the target of undesirable posttranslational modifications that compromise its function when occurring in critical subunits (Bulteau et al. 2001; Carrard et al. 2002). Lastly, there are pathological conditions in which malfunctioning of the UPS is not direct but rather a consequence of other cellular changes occurring in the disease. For example, conditions in which mitochondrial function is altered would lead to an energetic compromise because of the reduced production of ATP, and this in turn could diminish the UPS activity because of the high energetic requirements of this system (Hoglinger et al. 2003). 


\section{Chemical Modulation of the UPS}

As mentioned in the previous section, pharmacological inhibition of the proteasome has been successfully attained and drugs such as Bortezomib, a tripeptide that binds the catalytic site of the proteasome, are already approved for clinical use as anticancer treatments. In contrast, interventions aimed at up-regulating UPS activity, an outcome desirable in disorders with reduced activity of this system, have been less successful. To date, up-regulation of the UPS in vivo has been performed in most cases through genetic up-regulation of different components of this system. In fact, up-regulation of critical single subunits of the proteasome seems enough to increase the proteasome content and activity. Similar to autophagy, these manipulations have been shown effective in reducing intracellular protein inclusions and cellular toxicity. For example overexpression of a regulatory subunit of the 19S in cellular models of HD is sufficient to protect against neurodegeneration (Seo et al. 2007). Even in whole organisms, overexpression of specific factors like Rpn11 and CHIP in worms and flies leads to improved cellular homeostasis and prolonged lifespan (Oh et al. 2006; Min et al. 2008; Tonoki et al. 2009). The beneficial results of these manipulations justify the current search for chemical modulators able to up-regulate proteasome activity.

Modulation of the UPS is not reduced to mere chemical targeting of the catalytic core but could be exerted in other steps of this complex process. In this respect, some of the events that lead to degradation of proteins through the UPS may be more amenable to manipulation than others. For example, enzyme-catalyzed steps are attractive drug targets, in particular now that the structural properties of many of these enzymes are well known. When considering the enzymes involved in ubiquitination, chemical targeting of specific E3 enzymes may offer more selectivity than targeting of E1s, which will affect the total pool of ubiquitinated proteins. Likewise, the large number of cellular DUBs, each of them with preference for a particular type of linkage or active in specific cellular locations, guarantees that chemical targeting of these molecules may also allow some selectivity. Apart from enzyme targeting, polyubiquitin chain recognition has also been revealed recently as a suitable chemical target. For example ubistatin specifically binds interfaces between K48-linked ubiquitin molecules changing the conformation of the ubiquitin chain to prevent recognition by shuttle receptors and the proteasome. Although so far most of the molecules have been used to prevent UPS degradation, it is conceivable that similar strategies could be used to enhance the affinity of ubiquitin recognizing molecules for ubiquitin and favor their targeting to this proteolytic system.

\section{CONCLUDING REMARKS}

Sound evidence supports a critical role for the two main cellular proteolytic systems in quality control and in maintenance of cellular homeostasis. These systems function in a coordinated manner with the cellular chaperones, but recent studies also support the existence of a cross-talk between autophagy and the UPS. As described in this article, ubiquitin, a tag once thought exclusive to proteasome degradation, is also used for cargo selection by some forms of autophagy. Some of the ubiquitin recognizing molecules or shuttle factors, are shared by both proteolytic systems (e.g., p62 or ubiquilin can deliver ubiquitinated substrates to both to the proteasome and macroautophagy). The challenge is now to decipher the code that determines targeting through one system or the other. Cross-talk between these two systems may also exist at other levels. Cells respond to blockage of the UPS by up-regulating macroautophagy, whereas persistent blockage of macroautophagy has been shown to compromise UPS activity. Discovering these many layers of interaction between autophagy and the UPS could lead to the identification of new targets for therapeutic interventions.

Malfunctioning of the proteolytic systems has been now shown in numerous protein conformational disorders. Failure of the clearance mechanisms, once considered a consequence of the disease, has been shown to underlie the 
E. Wong and A.M. Cuervo

pathogenesis of some of these disorders. These findings have boosted the interest in developing pharmacological interventions to up-regulate the activity of the proteolytic systems. In light of the promising results observed on genetic manipulation of the proteolytic systems in animal models of different conformational disorders, it is predicted that compounds able to up-regulate the activity of the proteolytic systems could become an efficient future treatment for these devastating disorders.

\section{ACKNOWLEDGMENTS}

Work in our laboratory is supported by National Institutes of Health (NIH) grants from NIA (AG021904, AG031782), NIDKK (DK041918), NINDS (NS038370), a Glenn Foundation Award, and a Hirsch/Weill-Caulier Career Scientist Award.

\section{REFERENCES}

Adams J. 2004. The development of proteasome inhibitors as anticancer drugs. Cancer Cell 5: 417-421.

Ahlberg J, Glaumann H. 1985. Uptake-microautophagyand degradation of exogenous proteins by isolated rat liver lysosomes. Effects of $\mathrm{pH}$, ATP, and inhibitors of proteolysis. Exp Mol Pathol 42: 78-88.

Alves G, Forsaa EB, Pedersen KF, Dreetz Gjerstad M, Larsen JP. 2008. Epidemiology of Parkinson's disease. J Neurol 255: $18-32$.

Axe EL, Walker SA, Manifava M, Chandra P, Roderick HL, Habermann A, Griffiths G, Ktistakis NT. 2008. Autophagosome formation from membrane compartments enriched in phosphatidylinositol 3-phosphate and dynamically connected to the endoplasmic reticulum. J Cell Biol 182: 685-701.

Baboshina OV, Haas AL. 1996. Novel multiubiquitin chain linkages catalyzed by the conjugating enzymes E2EPF and RAD6 are recognized by $26 \mathrm{~S}$ proteasome subunit 5 . J Biol Chem 271: 2823-2831.

Bandyopadhyay U, Sridhar S, Kaushik S, Kiffin R, Cuervo AM. 2010. Novel regulators of chaperone-mediated autophagy. Mol Cell 39: 535-547.

Bandyopadhyay U, Kaushik S, Vartikovsky L, Cuervo AM. 2008. Dynamic organization of the receptor for chaperone-mediated autophagy at the lysosomal membrane. Mol Cell Biol 28: 5747-5763.

Baumeister W, Walz J, Zuhl F, Seemuller E. 1998. The proteasome: paradigm of a self-compartmentalizing protease. Cell 92: 367-380.

Bedford L, Hay D, Devoy A, Paine S, Powe DG, Seth R, Gray T, Topham I, Fone K, Rezvani N, et al. 2008. Depletion of $26 \mathrm{~S}$ proteasomes in mouse brain neurons causes neurodegeneration and Lewy-like inclusions resembling human pale bodies. J Neurosci 28: 8189-8198.

Ben-Saadon R, Zaaroor D, Ziv T, Ciechanover A. 2006. The polycomb protein Ring1B generates self atypical mixed ubiquitin chains required for its in vitro histone $\mathrm{H} 2 \mathrm{~A}$ ligase activity. Mol cell 8: 700-710.

Bennett E, Bence N, Jayakumar R, Kopito R. 2005. Global impairment of the ubiquitin-proteasome system by nuclear or cytoplasmic protein aggregates precedes inclusion body formation. Mol Cell 17: 351-365.

Betarbet R, Sherer TB, Greenamyre JT. 2005. Ubiquitinproteasome system and Parkinson's diseases. Exp Neurol 191: S17-27.

Bulteau AL, Lundberg KC, Humphries KM, Sadek HA, Szweda PA, Friguet B, Szweda LI. 2001. Oxidative modification and inactivation of the proteasome during coronary occlusion/reperfusion. J Biol Chem 276: 30057-30063.

Carrard G, Bulteau AL, Petropoulos I, Friguet B. 2002. Impairment of proteasome structure and function in aging. Int J Biochem Cell Biol 34: 1461-1474.

Chastagner P, Israel A, Brou C. 2008. AIP/Itch regulates Notch receptor degradation in the absence of ligand. PLoS One 3: e2735.

Chondrogianni N, Gonos ES. 2008. Proteasome activation as a novel antiaging strategy. IUBMB Life 60: 651-655.

Ciechanover A. 2005. Proteolysis: from the lysosome to ubiquitin and the proteasome. Nat Rev Mol Cell Biol 6: 79-87.

Cohen E, Dillin A. 2008. The insulin paradox: aging, proteotoxicity and neurodegeneration. Nat Rev Neurosci 9: 759-767.

Coux O, Tanaka K, Goldberg AL. 1996. Structure and functions of the 20S and 26S proteasomes. Annu Rev Biochem 65: $801-847$.

Crosas B, Hanna J, Kirkpatrick DS, Zhang DP, Tone Y, Hathaway NA, Buecker C, Leggett DS, Schmidt M, King RW, et al. 2006. Ubiquitin chains are remodeled at the proteasome by opposing ubiquitin ligase and deubiquitinating activites. Cell 127: 1401-1413.

Cuervo AM. 2010. Chaperone-mediated autophagy: Selectivity pays off. Trends Endocrinol Metab 21: 142-150.

Cuervo A, Dice J. 1996. A receptor for the selective uptake and degradation of proteins by lysosomes. Science 273: 501-503.

Cuervo AM, Stefanis L, Fredenburg R, Lansbury PTJ, Sulzer D. 2004. Impaired degradation of mutant $\alpha$-synuclein by chaperone-mediated autophagy. Science 305: $1292-$ 1295.

De Duve C, Wattiaux R. 1966. Functions of lysosomes. [Review]. Ann Rev Physiol 28: 435-492.

Deretic V. 2009. Links between autophagy, innate immunity, inflammation and Crohn's disease. Dig Dis 27: 246-251.

Deter RL, Baudhuin P, De Duve C. 1967. Participation of lysosomes in cellular autophagy induced in rat liver by glucagon. J Cell Biol 35: C11-16.

Dice J. 2007. Chaperone-mediated autophagy. Autophagy 3: 295-299.

Douglas PM, Summers DW, Cyr DM. 2009. Molecular chaperones antagonize proteotoxicity by differentially 
modulating protein aggregation pathways. Prion 3: 51-58.

Dubouloz F, Deloche O, Wanke V, Cameroni E, De Virgilio C. 2005. The TOR and EGO protein complexes orchestrate microautophagy in yeast. Mol Cell 19: 15-26.

Ferguson CJ, Lenk GM, Meisler MH. 2009. Defective autophagy in neurons and astrocytes from mice deficient in PI(3,5)P2. Hum Mol Genet 18: 4868-4878.

Finley D. 2009. Recognition and processing of ubiquitinprotein conjugates by the proteasome. Annu Rev Biochem 78: 477-513.

Finn P, Mesires N, Vine M, Dice JF. 2005. Effects of small molecules on chaperone-mediated autophagy. Autophagy 1: $141-145$.

Goldberg AL. 2003. Protein degradation and protection against misfolded or damaged proteins. Nature 18: 895-899.

Hailey DW, Rambold AS, Satpute-Krishnan P, Mitra K, Sougrat R, Kim PK, Lippincott-Schwartz J. 2010. Mitochondria supply membranes for autophagosome biogenesis during starvation. Cell 141: 656-667.

Hanna J, Hathaway NA, Tone Y, Elsasser S, Kirkpatrick DS 2006. Deubiquitinating enzyme Ubp6 functions noncatalytically to delay proteasomal degradation. Cell 127: 99-11.

Hara T, Nakamura K, Matsui M, Yamamoto A, Nakahara Y, Suzuki-Migishima R, Yokoyama M, Mishima K, Saito I, Okano H, et al. 2006. Suppression of basal autophagy in neural cells causes neurodegenerative disease in mice. Nature 441: 885-889.

Hershko A, Ciechanover A. 1998. The ubiquitin system. Anпu Rev Biochem 67: 610-621.

Hicke L, Schubert H, Hill CP. 2005. Ubiquitin-binding domains. Nature 6: 610-621.

Hochstrasser M. 1996. Ubiquitin-dependent protein degradation. Annu Rev Genet 30: 405-439.

Hoglinger GU, Carrard G, Michel PP, Medja F, Lombes A, Ruberg M, Friguet B, Hirsch EC. 2003. Dysfunction of mitochondrial complex I and the proteasome: interactions between two biochemical deficits in a cellular model of Parkinson's disease. J Neurochem 86: 12971307.

Hosokawa N, Hara T, Kaizuka T, Kishi C, Takamura A, Miura Y, Iemura S, Natsume T, Takehana K, Yamada N, et al. 2009. Nutrient-dependent mTORC1 association with the ULK1-Atg13-FIP200 complex required for autophagy. Mol Biol Cell 20: 1981-1991.

Ikeda F, Dikic I. 2008. Atypical ubiquitin chains: new molecular signals. 'Protein modifications: beyond the usual suspects' review series. EMBO Rep 9: 536-542.

Itakura E, Kishi C, Inoue K, Mizushima N. 2008. Beclin 1 forms two distinct phosphatidylinositol 3-kinase complexes with mammalian Atg14 and UVRAG. Mol Biol Cell 19: 5360-5372.

Iwata A, Riley BE, Johnston JA, Kopito RR. 2005. HDAC6 and microtubules are required for autophagic degradation of aggregated huntingtin. I Biol Chem 280: 40282-40292.

Jentsch S, Schlenker S. 1995. Selective protein degradation: A journey's end within the proteasome. Cell 82: 881-884.
Jin L, Williamson A, Banerjee S, Philipp I, Rape M. 2008. Mechanism of ubiquitin-chain formation by the human anaphase-promoting complex. Cell 133: 653-665.

Johnson ES, Ma PCM, Ota I, Varshavsky A. 1995. A proteolytic pathway that recognizes ubiquitin as a degradation signal. J Biol Chem 270: 17442-17456.

Kabuta T, Wada K. 2008. Aberrant interaction between Parkinson disease-associated mutant UCH-L1 and the lysosomal receptor for chaperone-mediated autophagy. J Biol Chem 283: 23731-22373.

Keck S, Nitsch R, Grune T, Ullrich O. 2003. Proteasome inhibition by paired helical filament-tau in brains of patients with Alzheimer's disease. J Neurochem 85: 115-122.

Keller J, Gee J, Ding Q. 2002. The proteasome in brain aging. Ageing Res Rev 1: 279-293.

Kim PK, Hailey DW, Mullen RT, Lippincott-Schwartz J. 2008. Ubiquitin signals autophagic degradation of cytosolic proteins and peroxisomes. Proc Natl Acad Sci 105: 20567-20574.

Kim HT, Kim KP, Lledias F, Kisselev AF, Scaglione KM, Skowyra D, Gygi SP, Goldberg AL. 2007. Certain pairs of ubiquitin-conjugating enzymes (E2s) and ubiquitinprotein ligases (E3s) synthesize nondegradable forked ubiquitin chains containing all possible isopeptide linkages. J Biol Chem 282: 17375-17386.

Kirkpatrick DS, Hathaway NA, Hanna J, Elsasser S, Rush J, Finley D, King RW, Gygi SP. 2006. Quantitative analysis of in vitro ubiquitinated cyclin B1 reveals complex chain topology. Nat Cell Biol 8: 700-710.

Klionsky DJ, Cregg JM, Dunn WA Jr, Emr SD, Sakai Y, Sandoval IV, Sibirny A, Subramani S, Thumm M, Veenhuis $\mathrm{M}$, et al. 2003. A unified nomenclature for yeast autophagy-related genes. Dev Cell 5: 539-545.

Koegl M, Hoppe T, Schlenker S, Ulrich HD, Mayer TU, Jentsch S. 1999. A novel ubiquitination factor, E4, is involved in multiubiquitin chain assembly. Cell 96: 635-644.

Koga H, Kaushik S, Cuervo AM. 2010. Protein homeostasis and aging: The importance of exquisite quality control. Ageing Res Rev doi:10.1016/j.arr.2010.02.001.

Komander D, Reyes-Turcu F, Licchesi JD, Odenwaelder P, Wilkinson KD, Barford D. 2009a. Molecular discrimination of structurally equivalent Lys 63-linked and linear polyubiquitin chains. EMBO J 10: 466-473.

Komander D, Urbe S, Clague MJ. 2009b. Breaking the chains: structure and function of the deubiquitinases. Nat Rev Mol Cell Biol 10: 550-563.

Komatsu M, Waguri S, Ueno T, Iwata J, Murata S, Tanida I, Ezaki J, Mizushima N, Ohsumi Y, Uchiyama Y, et al. 2005. Impairment of starvation-induced and constitutive autophagy in Atg7-deficient mice. J Cell Biol 169: 425-434.

Korolchuk VI, Mansilla A, Menzies FM, Rubinsztein DC. 2009. Autophagy inhibition compromises degradation of ubiquitin-proteasome pathway substrates. Mol Cell 33: 517-527.

Lam YA, Xu W, DeMartino GN, Cohen RE. 1997. Editing of ubiquitin conjugates by an isopeptidase in the $26 \mathrm{~S}$ proteasome. Nature 385: 737-740. 
E. Wong and A.M. Cuervo

Lamark T, Kirkin V, Dikic I, Johansen T. 2009. NBR1 and p62 as cargo receptors for selective autophagy of ubiquitinated targets. Cell Cycle 8: 1986-1990.

Landles C, Bates GP. 2004. Huntingtin and the molecular pathogenesis of Huntington's disease. Fourth in molecular medicine review series. EMBO Rep 5: 958-963.

Large AT, Goldberg MD, Lund PA. 2009. Chaperones and protein folding in the archaea. Biochem Soc Trans 37: 46-51.

Lee J-H, Yu W, Kumar A, Lee S, Mohan P, Peterhoff C, Wolfe D, Martinez-Vicente M, Massey A, Sovak G, et al. 2010. PS1 mutations in Alzheimer's Disease disrupt lysosomal proteolysis and autophagy. Cell 7: 1146-1158.

Levine B, Klionsky DJ. 2004. Development by self-digestion: Molecular mechanisms and biological functions of autophagy. Dev Cell 6: 463-477.

Long J, Gallagher TR, Cavey JR, Sheppard PW, Ralston SH, Layfield R, Searle MS. 2008. Ubiquitin recognition by the ubiquitin-associated domain of p62 involves a novel conformational switch. J Biol Chem 283: 5427-5440.

Maggi V, Hart K. 1973. Lysosomes and lysosomal enzymes in hearts of hamsters (BIO 14.6 and BBL x7) with congenital cardiomyopathy. Recent Adv Studies Cardiac Struct Metabol 3: 489-495.

Markossian KA, Kurganov BI. 2004. Protein folding, misfolding, and aggregation. Formation of inclusion bodies and aggresomes. Biochemistry (Mosc) 69: 971-984.

Martinez-Vicente M, Talloczy Z, Kaushik S, Massey A, Mazzulli J, Mosharov E, Hodara R, Fredenburg R, Wu D, Follenzi A, et al. 2008. Dopamine-modified alpha-synuclein blocks chaperone-mediated autophagy. J Clin Invest 118: 777-788.

Massey AC, Kaushik S, Sovak G, Kiffin R, Cuervo AM. 2006 Consequences of the selective blockage of chaperonemediated autophagy. Proc Nat Acad Sci 103: 5905-5910.

Meijer AJ, Codogno P. 2004. Regulation and role of autophagy in mammalian cells. Int J Biochem Cell Biol 36: $2445-2462$.

Min JN, Whaley RA, Sharpless NE, Lockyer P, Portbury AL, Patterson C. 2008. CHIP deficiency decreases longevity, with accelerated aging phenotypes accompanied by altered protein quality control. Mol Cell Biol 28: 4018-4025.

Mizushima N. 2005. The pleiotropic role of autophagy: From protein metabolism to bactericide. Cell Death Differ 12: 1535-1541.

Mizushima N, Ohsumi Y, Yoshimori T. 2002. Autophagosome formation in mammalian cells. Cell Struct Funct 27: $421-429$.

Mizushima N, Levine B, Cuervo AM, Klionsky DJ. 2008. Autophagy fights disease through cellular self-digestion. Nature 451: 1069-1075.

Mizushima N, Sugita H, Yoshimori T, Ohsumi Y. 1998. A new protein conjugation system in human. The counterpart of the yeast Apg12p conjugation system essential for autophagy. J Biol Chem 273: 33889-33892.

Morimoto RI. 2008. Proteotoxic stress and inducible chaperone networks in neurodegenerative disease and aging. Genes Dev 22: 1427-1438.

Murakami Y, Matsufuji S, Kameji T, Hayashi S, Igarashi K.1992. Ornithine decarboxylase is degraded by the
$26 \mathrm{~S}$ proteasome without ubiquitination. Nature 360: 597-599.

Murata S, Minami Y, Minami M, Chiba T, Tanaka K. 2001. CHIP is a chaperone-dependent $\mathrm{E} 3$ ligase that ubiquitylates unfolded protein. EMBO Rep 2: 1133-1138.

Noda NN, Kumeta H, Nakatogawa H, Satoo K, Adachi W, Ishii J, Fujioka Y, Ohsumi Y, Inagaki F. 2008. Structural basis of target recognition by Atg8/LC3 during selective autophagy. Genes Cells 13: 1211-1218.

Oh SW, Mukhopadhyay A, Dixit BL, Raha T, Green MR, Tissenbaum HA. 2006. Identification of direct DAF-16 targets controlling longevity, metabolism and diapause by chromatin immunoprecipitation. Nat Genet 38: 251-257.

Pickart CM, Cohen RE. 2004. Proteasomes and their kin: proteases in the machine age. Nat Rev Mol Cell Biol 5: 177-187.

Raasi S, Varadan R, Fushman D, Pickart CM. 2005. Diverse polyubiquitin interaction properties of ubiquitinassociated domains. Nat Struct Mol Biol 12: 708-714.

Ravid T, Hochstrasser M. 2008. Diversity of degradation signals in the ubiquitin-proteasome system. Nat Rev Mol Cell Biol 9: 679-690.

Ravikumar B, Duden R, Rubinsztein D. 2002. Aggregateprone proteins with polyglutamine and polyalanine expansions are degraded by autophagy. Hum Mol Genet 11: 1107-1117.

Ravikumar B, Moreau K, Jahreiss L, Puri C, Rubinsztein D. 2010. Plasma membrane contributes to the formation of pre-autophagosomal structures. Nat Cell Biol 12: 747-757.

Ravikumar B, Vacher C, Berger Z, Davies JE, Luo S, Oroz LG, Scaravilli F, Easton DF, Duden R, O’Kane CJ, et al. 2004. Inhibition of mTOR induces autophagy and reduces toxicity of polyglutamine expansions in fly and mouse models of Huntington disease. Nat Genet 36: 585-595.

Robinson PA. 2008. Protein stability and aggregation in Parkinson's disease. Biochem J 413: 1-13.

Rosser MF, Washburn E, Muchowski PJ, Patterson C, Cyr DM. 2007. Chaperone functions of the E3 ubiquitin ligase CHIP. J Biol Chem 282: 22267-22277.

Sakai Y, Koller A, Rangell LK, Keller GA, Subramani S. 1998. Peroxisome degradation by microautophagy in Pichia pastoris: identification of specific steps and morphological intermediates. J Cell Biol 141: 625-636.

Salvador N, Aguado C, Horst M, Knecht E. 2000. Import of a cytosolic protein into lysosomes by chaperonemediated autophagy depends on its folding state. J Biol Chem 275: 27447-27456.

Sarkar S, Ravikumar B, Rubinsztein DC. 2009. Autophagic clearance of aggregate-prone proteins associated with neurodegeneration. Methods Enzymol 453: 83-110.

Sarkar S, Flot RA, Berger Z, Imarisio S, Cordenier A, Pasco M, Cook L, Rubinsztein D. 2005. Lithium induces autophagy by inhibiting inositol monophosphatase. J Cell Biol 170: 1101-1111.

Seibenhener ML, Babu JR, Geetha T, Wong HC, Krishna NR, Wooten MW. 2004. Sequestosome 1/p62 is a polyubiquitin chain binding protein involved in ubiquitin proteasome degradaion. Mol Cell Biol 24: 8055-8068. 


\section{Cellular Clearance Mechanisms}

Seo H, Sonntag KC, Kim W, Cattaneo E, Isacson O. 2007. Proteasome activator enhances survival of Huntington's disease neuronal model cells. PLoS One 2: e238.

Shang F, Deng G, Liu Q, Guo W, Haas AL, Crosas B, Finley D, Taylor A. 2005. Lys6-modified ubiquitin inhibits ubiquitin-dependent protein degradation. $J$ Biol Chem 280: $20365-20374$.

Staub O, Rotin D. 2006. Role of ubiquitination in cellular membrane transport. Physiol Rev 86: 669-707.

Stefanis L, Larsen K, Rideout H, Sulzer D, Greene L. 2001. Expression of A53T mutant but not wild-type alphasynuclein in PC12 cells induces alterations of the ubiquitin-dependent degradation system, loss of dopamine release, and autophagic cell death. J Neurosci 21: 9549-9560.

Suzuki K, Ohsumi Y. 2010. Current knowledge of the pre-autophagosomal structure (PAS). FEBS Lett 584: $1280-1286$.

Tan JM, Wong ES, Dawson VL, Dawson TM, Lim KL. 2008a. Lysine 63-linked polyubiquitin potentially partners with p62 to promote the clearance of protein inclusions by autophagy. Autophagy 4: 251-253.

Tan JM, Wong ES, Kirkpatrick DS, Pletnikova O, Ko HS, Tay SP, Ho MW, Troncoso J, Gygi SP, Lee MK, et al. 2008b. Lysine 63-linked polyubiquitination promotes the formation and autophagic clearance of protein inclusions associated with neurodegenerative diseases. Hum $\mathrm{Mol}$ Genet 17: 431-439.

Thrower JS, Hoffman L, Rechsteiner M, Pickart CM. 2000. Recognition of the polyubiquitin proteolytic signal. EMBO J 19: 94-102.

Tolkovsky AM. 2009. Mitophagy. Biochim Biophys Acta 1793: 1508-1515.

Tonoki A, Kuranaga E, Tomioka T, Hamazaki J, Murata S, Tanaka K, Miura M. 2009. Genetic evidence linking agedependent attenuation of the $26 \mathrm{~S}$ proteasome with the aging process. Mol Cell Biol 29: 1095-1106.

Tuttle DL, Dunn WA Jr. 1995. Divergent modes of autophagy in the methylotrophic yeast Pichia pastoris. J Cell Sci 108: 25-35.

Varadan R, Assfalg M, Raasi S, Pickart CM, Fushman D. 2005. Structural determinants for selective recognition of a Lys48-linked polyubiquitin chain by a UBA domain. Mol Cell 18: 687-698.

Verma R, Aravind L, Oania R, McDonald WH, Yates JRI. 2002. Role of Rpn11 metalloprotease in deubiquitination and degradation by the $26 \mathrm{~S}$ protease. Science 298: 611-615.

Wang Y, Martinez-Vicente M, Kruger U, Kaushik S, Wong E, Mandelkow EM, Cuervo AM, Mandelkow E. 2009. Tau fragmentation, aggregation and clearance: The dual role of lysosomal processing. Hum Mol Genet 18: 4153-4170.

Waters S, Marchbank K, Solomon E, Whitehouse C, Gautel M. 2009. Interactions with LC3 and polyubiquitin chains link nbr1 to autophagic protein turnover. FEBS Lett 583: $1846-1852$.

Willis MS, Schisler JC, Portbury AL, Patterson C. 2009. Build it up-Tear it down: Protein quality control in the cardiac sarcomere. Cardiovasc Res 81: 439-448.

Wong E, Cuervo AM. 2010. Autophagy gone awry in neurodegenerative diseases. Nat Neurosci 13: 806-811.

Wong ES, Tan JM, Soong WE, Hussein K, Nukina N, Dawson VL, Dawson TM, Cuervo AM, Lim KL. 2008 Autophagy-mediated clearance of aggresomes is not a universal phenomenon. Hum Mol Genet 17: 2570-2582.

Xu P, Duong DM, Seyfried NT, Cheng D, Xie Y, Robert J, Rush J, Hochstrasser M, Finley D, Peng J. 2009. Quantitative proteomics reveals the function of unconventional ubiquitin chains in proteasomal degradation. Cell 137: $133-145$.

Yang Z, Klionsky DJ. 2009. An overview of the molecular mechanism of autophagy. Curr Top Microbiol Immunol 335: $1-32$.

Yang XY, Wood NQ, Latchman DS. 2009. Molecular basis of Parkinson's disease. Neuroreport 20: 150-156.

Yao T, Cohen RE. 2002. A cryptic protease couples deubiquitination and degradation by the proteasome. Nature 419: 403-407.

Zhang C, Cuervo AM. 2008. Restoration of chaperone-mediated autophagy in aging liver improves cellular maintenance and hepatic function. Nat Med 14: 959-965. 


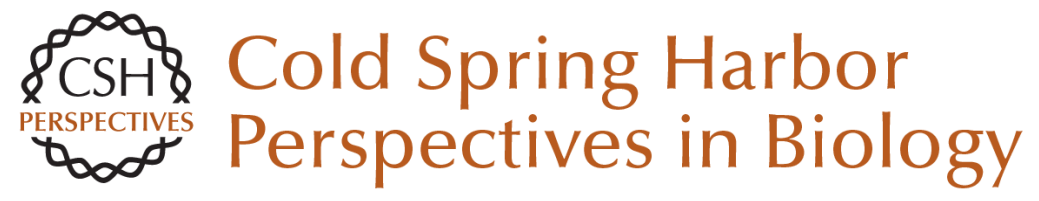

\section{Integration of Clearance Mechanisms: The Proteasome and Autophagy}

Esther Wong and Ana Maria Cuervo

Cold Spring Harb Perspect Biol 2010; doi: 10.1101/cshperspect.a006734 originally published online November 10, 2010

\section{Subject Collection Protein Homeostasis}

Proteome-Scale Mapping of Perturbed

Proteostasis in Living Cells

Isabel Lam, Erinc Hallacli and Vikram Khurana

Pharmacologic Approaches for Adapting Proteostasis in the Secretory Pathway to

Ameliorate Protein Conformational Diseases Jeffery W. Kelly

Cell-Nonautonomous Regulation of Proteostasis in Aging and Disease

Richard I. Morimoto

The Autophagy Lysosomal Pathway and

Neurodegeneration

Steven Finkbeiner

Functional Modules of the Proteostasis Network Gopal G. Jayaraj, Mark S. Hipp and F. Ulrich Hartl

Protein Solubility Predictions Using the CamSol Method in the Study of Protein Homeostasis Pietro Sormanni and Michele Vendruscolo

Recognition and Degradation of Mislocalized Proteins in Health and Disease

Ramanujan S. Hegde and Eszter Zavodszky

The Nuclear and DNA-Associated Molecular Chaperone Network

Zlata Gvozdenov, Janhavi Kolhe and Brian C. Freeman
The Amyloid Phenomenon and Its Significance in Biology and Medicine

Christopher M. Dobson, Tuomas P.J. Knowles and Michele Vendruscolo

A Chemical Biology Approach to the Chaperome

in Cancer--HSP90 and Beyond

Tony Taldone, Tai Wang, Anna Rodina, et al.

Proteostasis in Viral Infection: Unfolding the Complex Virus-Chaperone Interplay Ranen Aviner and Judith Frydman

The Proteasome and Its Network: Engineering for Adaptability Daniel Finley and Miguel A. Prado

Functional Amyloids Daniel Otzen and Roland Riek

Chaperone Interactions at the Ribosome Elke Deuerling, Martin Gamerdinger and Stefan G. Kreft

Mechanisms of Small Heat Shock Proteins Maria K. Janowska, Hannah E.R. Baughman, Christopher N. Woods, et al.

Structure, Function, and Regulation of the Hsp90 Machinery

Maximilian M. Biebl and Johannes Buchner

For additional articles in this collection, see http://cshperspectives.cshlp.org/cgi/collection/

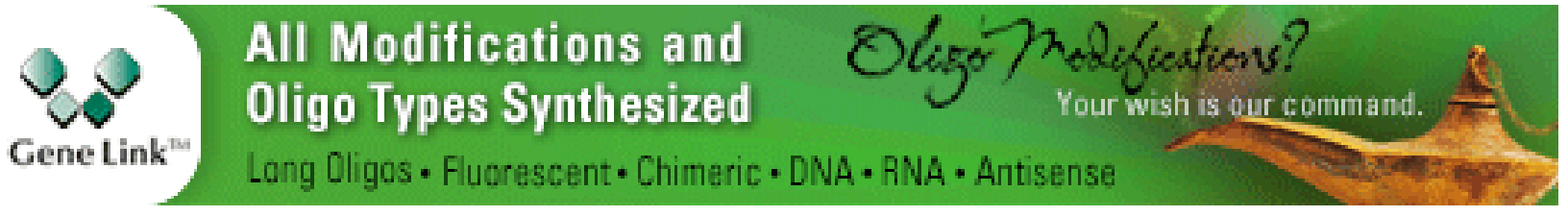


For additional articles in this collection, see http://cshperspectives.cshlp.org/cgi/collection/

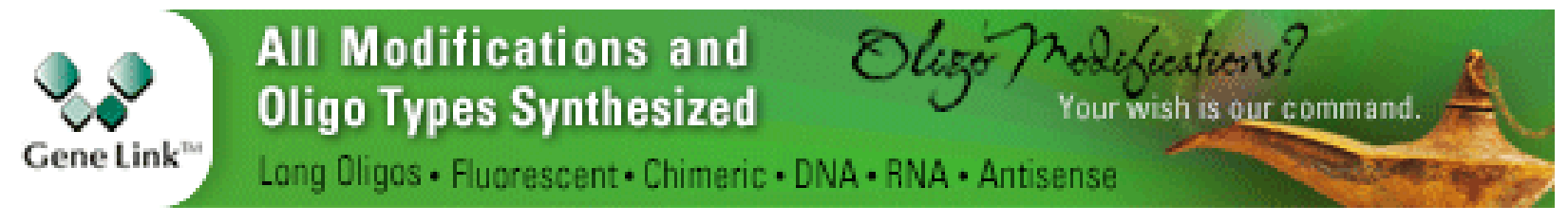

Copyright @ 2010 Cold Spring Harbor Laboratory Press; all rights reserved 